\title{
Commentary \\ Extracorporeal life support for severe drug-induced cardiotoxicity: a promising therapeutic choice
}

\author{
Hutan Ashrafian and Thanos Athanasiou
}

Department of Biosurgery and Surgical Technology, Imperial College London, Imperial College Healthcare NHS Trust at St Mary's Hospital, Praed Street, London, W2 1NY, United Kingdom

Corresponding author: Thanos Athanasiou, t.athanasiou@imperial.ac.uk

Published: 24 September 2009

Critical Care 2009, 13:187 (doi:10.1186/cc8046)

This article is online at http://ccforum.com/content/13/5/187

(c) 2009 BioMed Central Ltd

See related research by Daubin et al., http://ccforum.com/content/13/4/R138

\begin{abstract}
Drug-induced cardiovascular failure is an acute condition that is associated with significant healthcare consequences. Antidotes and supportive treatments are the initial measures to manage cardiotoxicity, but if severe drug-induced cardiotoxicity develops, usually as cardiovascular shock or cardiac arrest, then circulatory assistance may have an important role in the therapeutic algorithm. A number of circulatory assistance techniques have been increasingly employed to treat severe drug-induced cardiotoxicity. These include extracorporeal membrane oxygenation, intra-aortic balloon pumping and standard cardiopulmonary bypass. Recently, extracorporeal life support (ECLS) has been developed to provide percutaneous cardiopulmonary support peripherally without the need for sternotomy. ECLS can provide successful treatment of severe drug-induced cardiotoxicity in selected cases. This technique may be associated with complications of limb ischaemia, haemorrhage and embolism. An increased consideration of ECLS within the context of rigorous clinical studies and strong evidence can add to its future use for severe drug-induced cardiotoxicity.
\end{abstract}

In their recent study, Daubin and colleagues [1] highlight the management of drug-induced cardiotoxicity. Cardiovascular failure as a result of drug poisoning is an acute condition that is associated with significant healthcare consequences. Although cardiovascular drugs account for $3.5 \%$ of all drug poisoning cases, their mortality impact can be disproportionately high (16.38\% of deaths) [2]. Of these drugs, those with membrane stabilising activity impede depolarisation and are associated with increased mortality [3]. There are several modes of severe cardiotoxicity presentation, including persistent hypotension, cardiogenic shock, atrio-ventricular block, asystole, pulseless ventricular tachycardia and ventricular fibrillation.

Antidotes and supportive treatments are the initial measures to manage cardiotoxicity, but if severe drug-induced cardio- toxicity develops, usually as cardiovascular shock or cardiac arrest, then circulatory assistance may have an important role in the therapeutic algorithm [4]. This provides temporal circulatory support to the vital organs whilst unloading the myocardium to encourage myocardial recovery. A number of circulatory assistance techniques have been increasingly employed to treat severe drug-induced cardiotoxicity. These include extracorporeal membrane oxygenation, where a venous-venous circuit can treat hypoxaemia in the absence of mechanical circulatory support. Intra-aortic balloon pumping can be used percutaneously to increase cardiac output whilst decreasing myocardial oxygen demand through a counterpulsating aortic balloon. In the past, standard cardiopulmonary bypass was used to provide definitive oxygenation and mechanical support, although it requires full sternotomy. Recently, however, the technique of extracorporeal life support (ECLS) has been developed to provide percutaneous cardiopulmonary support peripherally without the need for sternotomy [5].

Daubin and colleagues report a single-institution, retrospective review of 17 adult cardiotoxic drug-overdose patients who received ECLS for prolonged cardiac arrest or refractory shock [1]. Their 10-year experience reflects an increased familiarity of performing this procedure compared to other techniques of cardiac assistance in the setting of druginduced cardiotoxicity. Despite $59 \%$ of patients suffering cardiac toxicity as a result of hazardous drugs with membrane stabilizing activity, they quote favourable results of $76 \%$ of individuals being discharged to hospital without sequelae. This is maintained with relatively long ECLS duration times, with a mean of 4.5 days compared to less than 24 hours for the majority of cases requiring cardiopulmonary bypass in previous reports [6].

ECLS $=$ extracorporeal life support. 
The timing of ECLS commencement after hospital admission reported by Daubin and colleagues was over 15 hours in four individuals with refractory shock. Although this is much longer than equivalent time-to-cardiopulmonary bypass in reported series, the patients had a satisfactory outcome. These longer times to treatment may reflect the delayed cardiotoxic presentation of some cardiotropic drugs seen in overdosed patients $[7,8]$.

Daubin and colleagues included patients with refractory shock and cardiac arrest in their cohort and it is important to keep in mind that these conditions may be caused by different pathologies. In 2007 Megarbane and colleagues [9] presented the outcomes of 12 patients undergoing ECLS for refractory cardiac arrest after cardiotoxic poisoning. In this prospective study only $25 \%$ of patients survived ICU discharge after ECLS. This comparatively poor outcome needs further investigation and may be related to shorter mean ECLS times of 2.3 days versus 4.5 days for Daubin and colleagues.

ECLS can be associated with a number of cannulationrelated complications and Daubin and colleagues report their experience of limb ischaemia, haemorrhage, femoral thrombus and inferior vena caval thrombus. This is consistent with other studies of emergency extracorporeal circulation $[5,10]$ despite the use of percutaneous Seldinger techniques and protective manoeuvres such as additional limb perfusion. The high rate of vascular complications, however, requires consideration, particularly as Megarbane and colleagues [9] quote no reports of limb ischaemia. This again may be related to the shorter duration of ECLS, but also requires the assessment of anatomical cannulation site, technique, equipment and hospital setting. One case required left atrial decompression (via balloon-septostomy); although this has been previously reported for the ECLS procedure [5], it has not previously been described in the context of poisoning.

As a result of the finding that all ECLS survivors were discharged without significant cardio-vascular or neurological sequelae, the authors comment that ECLS is a safe and efficient therapeutic option for critically ill poisoned patients. In the authors' experience ECLS was applicable in a variety of hospital settings, including the ICU, emergency department and operating theatres.

There are a number of important questions to be addressed in analyzing this experience. First, what are the indications of ECLS and what are the benefits compared to other methods of circulatory assistance? Should the choice of ECLS depend on institution preference or depend on national/ international guidelines? This requires clear outcome data and stronger levels of evidence to guide management decisions. Secondly, which vessels should be cannulated in each patient to decrease complications and in which hospital locations should these procedures be performed? Thirdly, which healthcare professionals should decide on the appropriateness and technique of ECLS cannulation and how much training is necessary to ensure that practitioners can perform this procedure reliably and safely?

The future use of ECLS in treating cardiotoxic drug overdose patients depends on identifying the patients who will benefit most from this procedure whilst making the available technology safer and simpler to use. This will require larger clinical studies to stratify patients according to risk and will entail both improved techniques and equipment. Surgeons will require adequate training on animal models and advanced simulators to be more confident with emergency percutaneous or cut-down techniques of vascular access. Cardiopulmonary bypass equipment for cannulation will require enhancement to minimise embolism and haemorrhage. Importantly, however, there is strong need for close collaboration and communication between intensivists, surgeons, perfusionists and toxicologists. Daubin and colleagues demonstrated that ECLS can successfully treat cardiotoxic druginduced shock and arrest. An increased consideration of ECLS within the context of rigorous clinical studies and strong evidence can add to its future use for severe druginduced cardiotoxicity.

\section{Competing interests}

The authors declare that they have no competing interests.

\section{References}

1. Daubin C, Lehoux P, Ivascau C, Tasle M, Bousta M, Lepage O, Quentin C, Massetti M, Charbonneau P: Extracorporeal life support in severe drug intoxication: a retrospective cohort study of seventeen cases. Crit Care 2009, 13:R138.

2. Bronstein AC, Spyker DA, Cantilena LR, Jr., Green JL, Rumack BH, Heard SE: 2007 Annual Report of the American Association of Poison Control Centers' National Poison Data System (NPDS): 25th Annual Report. Clin Toxicol (Phila) 2008, 46:927-1057.

3. Henry JA, Cassidy SL: Membrane stabilising activity: a major cause of fatal poisoning. Lancet 1986, 1:1414-1417.

4. Albertson TE, Dawson A, de Latorre F, Hoffman RS, Hollander JE, Jaeger A, Kerns WR, 2nd, Martin TG, Ross MP: TOX-ACLS: toxicologic-oriented advanced cardiac life support. Ann Emerg Med 2001, 37(4 Suppl):S78-90.

5. Massetti M, Tasle M, Le Page O, Deredec R, Babatasi G, Buklas D, Thuaudet S, Charbonneau P, Hamon M, Grollier G, Gerard JL, Khayat A: Back from irreversibility: extracorporeal life support for prolonged cardiac arrest. Ann Thorac Surg 2005, 79:178183; discussion 183-174.

6. Purkayastha S, Bhangoo P, Athanasiou T, Casula R, Glenville B, Darzi AW, Henry JA: Treatment of poisoning induced cardiac impairment using cardiopulmonary bypass: a review. Emerg Med J 2006, 23:246-250.

7. Boehnert MT, Lovejoy FH Jr: Value of the QRS duration versus the serum drug level in predicting seizures and ventricular arrhythmias after an acute overdose of tricyclic antidepressants. N Engl J Med 1985, 313:474-479.

8. Love JN, Howell JM, Litovitz TL, Klein-Schwartz W: Acute beta blocker overdose: factors associated with the development of cardiovascular morbidity. J Toxicol Clin Toxicol 2000, 38:275281.

9. Megarbane B, Leprince P, Deye N, Resiere D, Guerrier G, Rettab S, Theodore J, Karyo S, Gandjbakhch I, Baud FJ: Emergency feasibility in medical intensive care unit of extracorporeal life support for refractory cardiac arrest. Intensive Care Med 2007, 33:758-764.

10. Magovern GJ Jr, Simpson KA: Extracorporeal membrane oxygenation for adult cardiac support: the Allegheny experience. Ann Thorac Surg 1999, 68:655-661. 